\title{
Evaluating the Effect of Weft Yarn Characteristics on Fabric Texture Using Image Analysis Techniques Singh JP*
}

Department of Textile Technology, U.P. Textile Technology Institute Kanpur, India

\begin{abstract}
In this research work, an objective evaluation method for assessing aesthetic appearance of apparel based fabric having five different wefts by image processing technique is suggested. Surface texture characteristics such as energy, entropy, inertia have been estimated by different image processing techniques. Fast fourier transform (FFT) power spectrum method is used to estimate the surface texture in terms of fractal dimension (FD). Subjective evaluation of appearance for different fabric samples has been carried out by experts and its correlation with image processing based texture characteristics is determined. Effect of five different weft yarn characteristics on the fabric appearance is investigated. Negative correlation is obtained between fractal dimension \& energy while rest of the parameters have resulted good positive correlation. The surface of the fabric with polyester textured filament yarn showed the uniform texture while fabric with cotton slub weft exhibited the rough texture. The results also suggest that all the texture results from image analysis based objective methods are very well correlated with the subjective texture results. A preliminary study was also done to derive the textural parameters from the geometrical parameters of the slub yarn. But the textural parameters do not seem equal to any of the geometrical parameters of the slub yarn. For this, probably a more detailed study is needed with different quality of slub yarn. The research work is in progress to give a mathematical relation between the fabric texture and slub yarn geometrical parameters.
\end{abstract}

Keywords: Texture; Fractal dimension; Weft yarn; Slub yarn; Textured polyester yarn

\section{Introduction}

Apparel based fabrics are popular particularly for their textural properties like fine visual appearance, pleasant to touch, soft hand and comfortable to wear behavior. The appearance of apparel based fabric is normally evaluated by highly experienced people by subjective methods. Although these methods are useful in the overall assessment of textile products, however, they are time consuming and the results lack reproducibility. Many researchers [1-3] have questioned on the reliability and usefulness of these techniques and lead to the development of a more realistic instrumental method to quantify apparel based fabric appearance value. It is thought to be very useful for quality assurance, process control and product development in manufacturing of apparel based fabrics. The textural properties of fabrics are some of the key factors that can be altered by the manufacturers to influence consumers at the point of sale.

Producing different variety of fabric is the main concern on the manufacturers so that they can satisfy the growing demand of the customers. Fabric texture is an important properties that can be altered easily to add variety to the fabrics. Producing fabric by using different types of yarn in the warp has some limitation because it has to pass though the healds and reed. These limitations can be overcome by the weft yarn which provides freedom to use any type of yarn in the fabric. So, the different types of the weft yarn can be used to alter the properties of fabric without facing production and quality difficulties [4]. The exact effect of the changes in yarn characteristics on the fabric texture needs to be understood for better quality of the fabric. In this research work, an attempt has been made to change the fabric texture by changing the weft yarn in the fabric and to correlate these texture changes with the yarn parameters. The paper also aims at verifying the results of image analysis based objective method for texture evaluation with the traditional subjective method.

\section{Theory of Aesthetic Characterization}

\section{Texture analysis}

Texture describes the surface properties, i.e. smoothness or roughness and the uniformity of the fabric surface. Wavelet transform [4-7] is capable of extracting features that may be used to distinguish between different fabric textures. The spatial grey level co-occurrence measurement method, a statistical approach, can be used for texture measurement. The image size is 512 by 512 pixels The spatial grey level co-occurrence probability function $f(i, j, d, a)$ is a second-order probability density function; it is the relative frequency with which two pixels separated by a distance $d$ in the $a$ direction occur on the image one with $i$ grey level and the other with $j$ grey level. From this definition one can calculate co-occurrence matrices in the directions $0^{\circ}, 45^{\circ}, 90^{\circ}$ and $135^{\circ}$ and from these matrices the following parameters can be calculated.

$$
\begin{aligned}
& \text { Inertia }=\sum_{i} \sum_{j}\left[(i-j)^{2} \frac{f(i, j, d, a)}{S}\right] \\
& \text { Energy }=\sum_{i} \sum_{j}\left[\frac{f(i, j, d, a)}{S}\right]^{2} \\
& \text { Entropy }=-\sum_{i} \sum_{j}\left[\frac{f(i, j, d, a)}{S} \log \left(\frac{f(i, j, d, a)}{S}\right)\right]
\end{aligned}
$$

Where

$$
S=\sum_{i} \sum_{j} f(i, j, d, a)
$$

Energy illustrates the homogeneity of the structure: high energy means more homogeneous texture and vice versa. Similarly entropy

*Corresponding author: Singh JP, Department of Textile Technology, U.P. Textile Technology Institute Kanpur, India, Tel: 0512253 1814; E-mail: jpsingh.iitd@gmail.com

Received June 09, 2016; Accepted July 04, 2016; Published July 11, 2016

Citation: Singh JP (2016) Evaluating the Effect of Weft Yarn Characteristics on Fabric Texture Using Image Analysis Techniques. J Textile Sci Eng 6: 261 doi:10.4172/2165-8064.1000261

Copyright: (C) 2016 Singh JP. This is an open-access article distributed under the terms of the Creative Commons Attribution License, which permits unrestricted use, distribution, and reproduction in any medium, provided the original author and source are credited. 
Citation: Singh JP (2016) Evaluating the Effect of Weft Yarn Characteristics on Fabric Texture Using Image Analysis Techniques. J Textile Sci Eng 6: 261. doi:10.4172/2165-8064.1000261

Page 2 of 6

and inertia depict structural disorder and local variations respectively; large entropy is indicative of more disordered structure, and high inertia means high local variations. The parameters are based on statistics and information theory.

\section{The estimation of fractal dimension}

Bergmann et al. [8] proved that the tactile surface property, such as roughness, can be evaluated by the fractal dimension of the surface. Since Mandelbrot [9] first proposed the term 'fractal', there are many different definitions and different measurements for the fractal dimension. The method we used for fractal dimension estimation is the power spectrum method [10].

The power spectrum estimation is far more accurate than the other methods. As shown in equation (4), the power spectrum $\mathrm{P}$ is proportional to the certain power $\beta$ of the radial frequency $\omega$ [11].

$$
\mathrm{P}(\omega) \propto \omega^{-\beta}
$$

Where $\omega \geq 0$. The fractal dimension $\mathrm{D}$ of an image is related to the exponent $\beta$ in above equation.

$$
D=\frac{8-\beta}{2}
$$

The general algorithm of FD power spectrum estimation is shown in the below figures. The first step is to read the information from a binary image file and then store the information into a matrix. Using the fast Fourier transform (FFT) the information is transformed to the spatial frequency domain [12]. The power spectrum is calculated in order to remove the imaginary part of the FFT result. In the fourth block, the power spectrum is cut into several radial slices and integrated respectively.

The final step consists of determining the exponent $\beta$ by using linear regression to find the slopes of the fourth step results on a loglog scale, and applying equation (5) to compute D. It is robust to the linear transformation of the image data and the scaling of the image theoretically. The experiment results in the next section also proved its good performance.

\section{Materials and Methods}

\section{Materials}

Fabric samples were manufactured on the rapier weaving machines (TD - 736A). The details of the sample were given in Table 1, and the images are shown in Figure 1.

Slub yarn: Slub yarn used in this research work is produced in controlled manner on special ring frame. Three important parameters, total slub length percentage, total slub distance percentage and percentage of $\mathrm{CV}$, of the slub yarn were evaluated using conventional method. The results were used as a preliminary study to correlate these parameters with the change in the texture of the fabric Figure 2.

$$
\begin{aligned}
& \text { Total slublength } \%=\frac{\sum_{i=1}^{n} S L_{i}}{T L} * 100 \\
& \text { Total slublength } \% \frac{\sum S D}{T L} * 100
\end{aligned}
$$

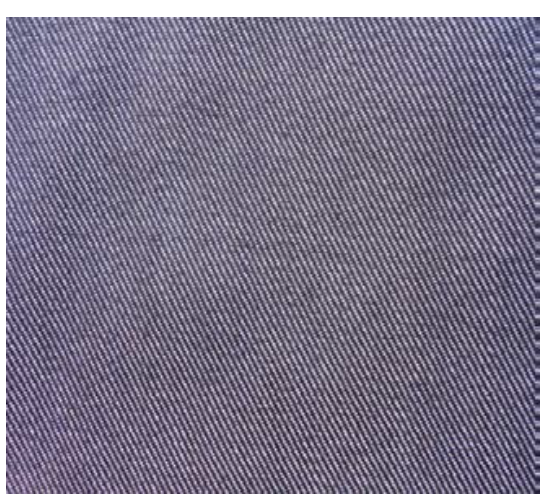

(a)

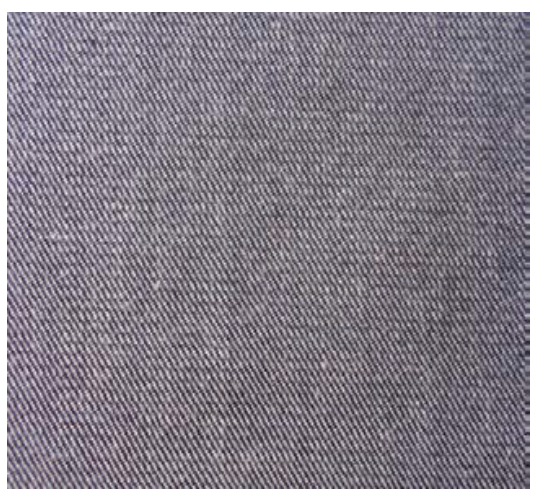

(b)

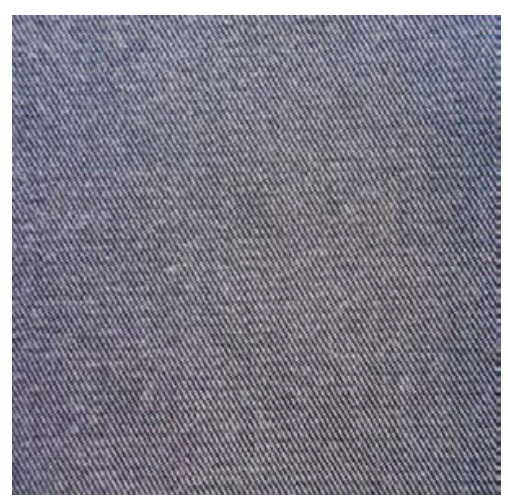

(c)

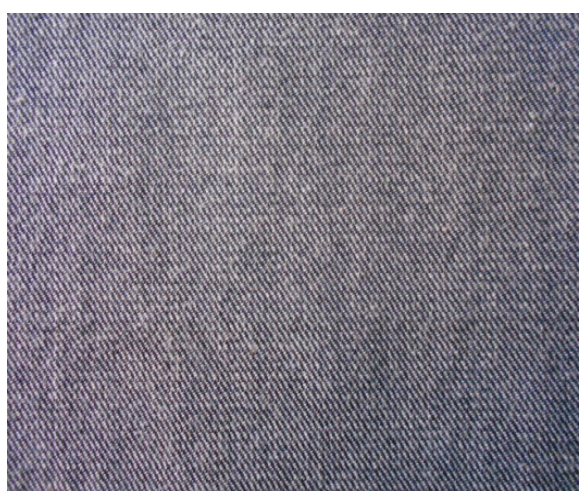

(d)

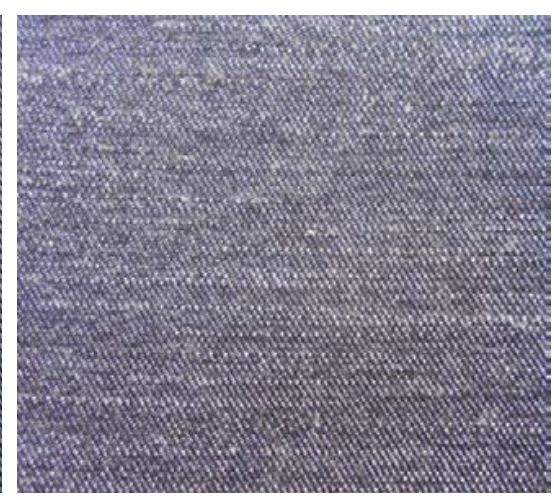

(e)

Figure 1: Fabric samples having (a) polyester textured yarn (b) combed cotton yarn (c) P/V yarn (d) cotton lycra yarn (e) cotton slub yarn in weft. 
Citation: Singh JP (2016) Evaluating the Effect of Weft Yarn Characteristics on Fabric Texture Using Image Analysis Techniques. J Textile Sci Eng 6: 261. doi:10.4172/2165-8064.1000261

Page 3 of 6

Where SL: Slub length, SD: Slub diameter, and TL: Total length measured.

Methods: Images of 5 fabric samples were taken using an image acquisition box and the method described by researchers [13] and as shown in figure. Energy, Entropy and Inertia were determined by using spatial grey level co-occurrence measurement method as given in equations 1, 2 and 3 respectively. FD was calculated by using FFT. The textural parameters (Energy, Entropy and Inertia) and fractal dimension (FD) were evaluated by using image analysis techniques according to the algorithm given in Figures 3 and 4 respectively. Energy is multiplied by a factor $10^{5}$ and Entropy is divided by a factor 10 to represent the data graphically.

Based on these flow diagrams, Maltab program have been written to calculate the texture and fractal terms.

Subjective evaluation of surface texture: The selection of judges for subjective evaluation is very crucial as their opinion should match the general opinion of user as well as the manufacturer. The person

\begin{tabular}{|c|c|c|c|c|c|}
\hline S.No & EPI & PPI & Warp count (Ne) & Weft count (Ne) & Weft yarn type \\
\hline S1 & 62 & 43 & $30 / 2 \mathrm{P} / \mathrm{W}$ & $30 / 2^{*}$ & Polyester textured yarn \\
\hline S2 & 62 & 43 & $30 / 2 \mathrm{P} / \mathrm{C}$ & $30 / 2$ & Combed cotton yarn \\
\hline S3 & 62 & 43 & $30 / 2 \mathrm{P} / \mathrm{P}$ & $30 / 2$ & $\mathrm{P} / \mathrm{N}^{* *}$ yarn \\
\hline S4 & 62 & 43 & $30 / 2 \mathrm{P} / \mathrm{N}$ & $30 / 2$ & Cotton lycra yarn \\
\hline S5 & 62 & 43 & $30 / 2 \mathrm{P} / \mathrm{N}$ & $30 / 2$ & $2 / 1$ twill \\
\hline
\end{tabular}

"Equivalent to $2 / 30 \mathrm{Ne},{ }^{\text {**}} \mathrm{P} / \mathrm{V}$ : Polyester/viscose, EPI: ends per inches, PPI: picks per inches.

Table 1: Sample constructional details.

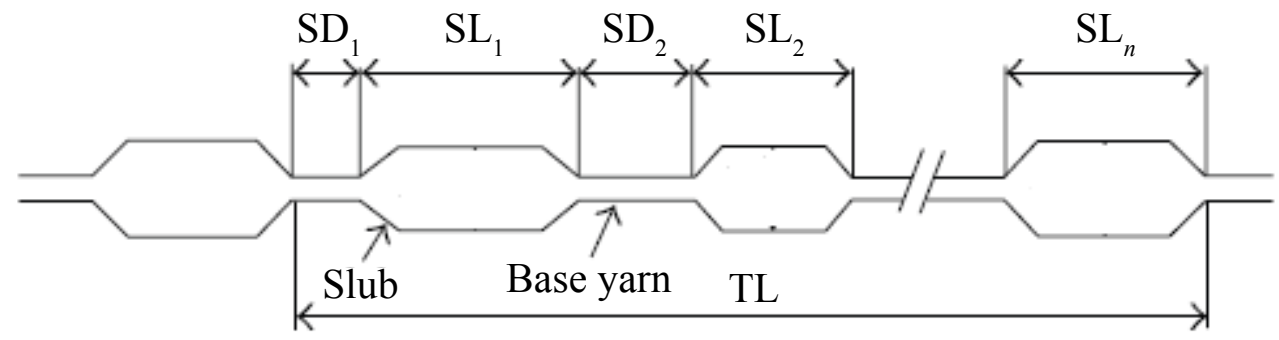

Figure 2: Geometrical parameters of slub yarn (El-khalek, El-Bealy, and El-Deeb, 2014).

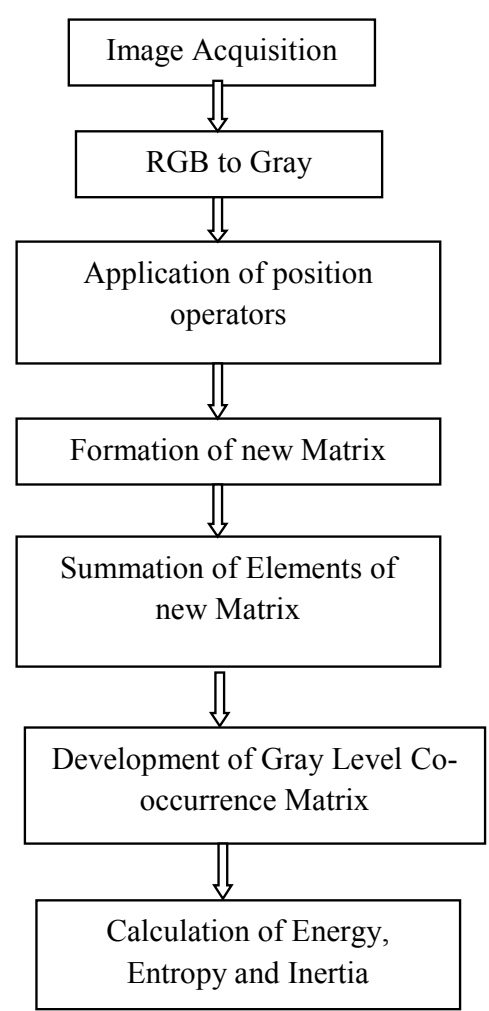

Figure 3: Flow diagram for calculating Energy, Entropy and Inertia.

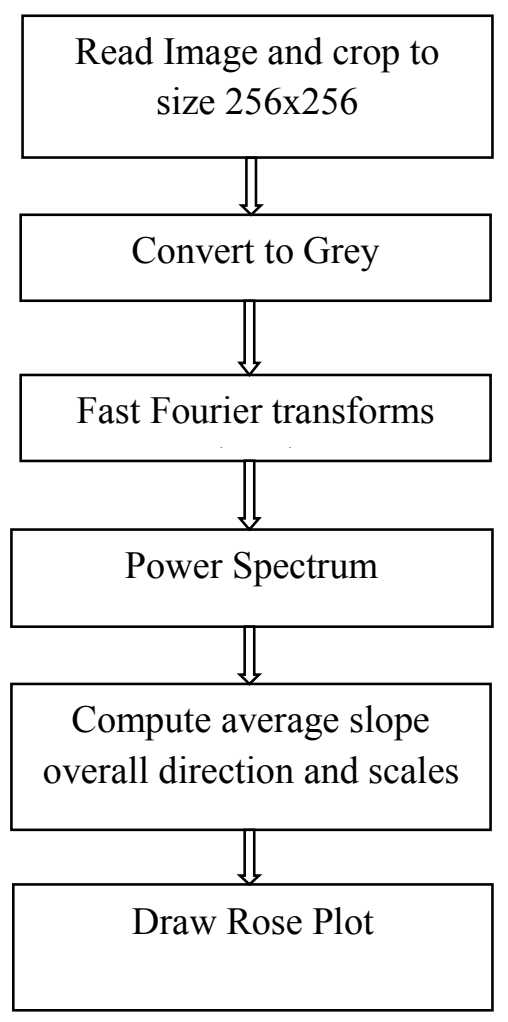

Figure 4: Flow diagram for calculating Fractal dimension. 

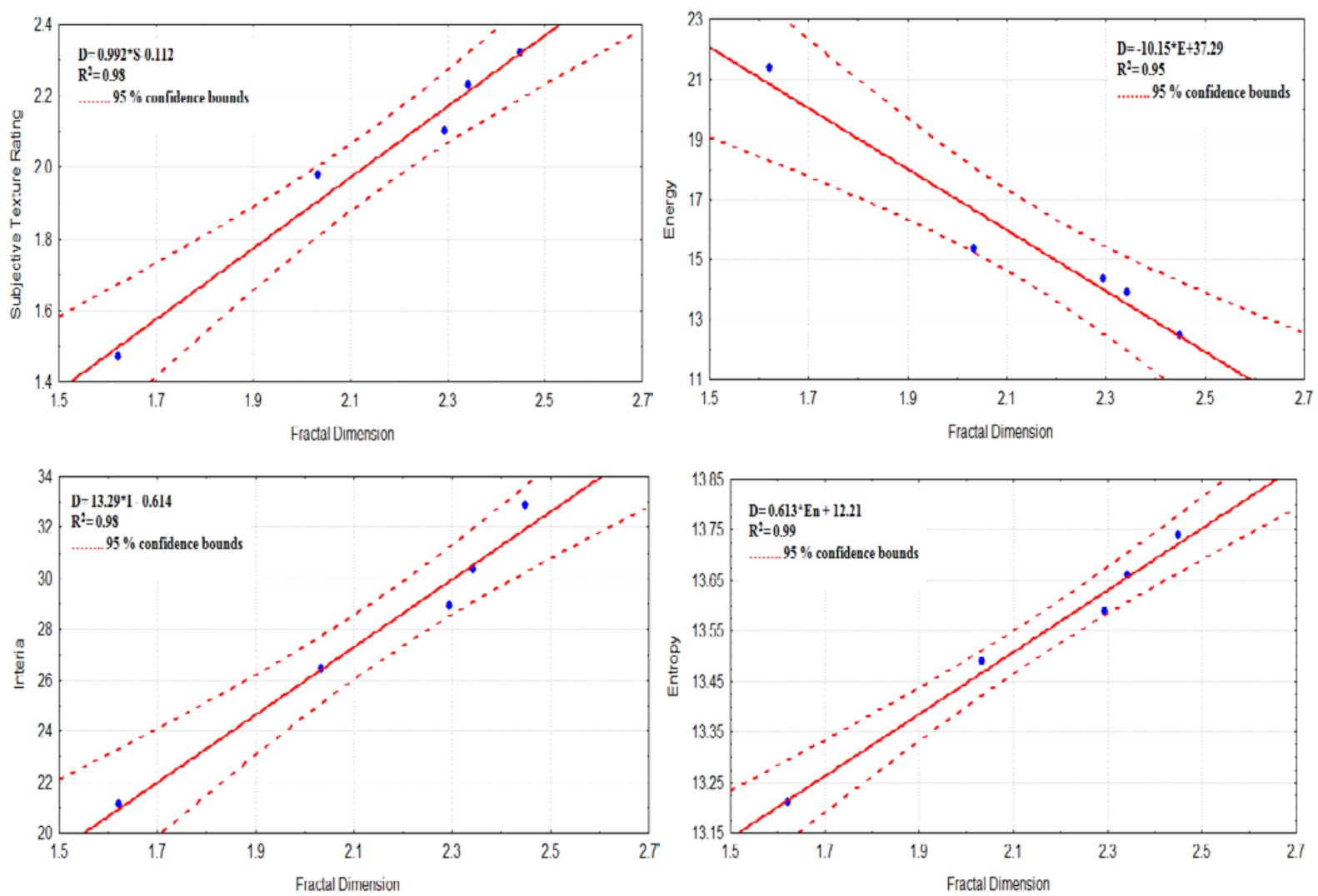

Figure 5: Correlation between Fractal Dimension and various texture descriptors (a) Subjective Texture Rating (b) Energy (c) Inertia (e) Entropy.

working in the sample design and development section of a factory is a link between buyer and manufacturer as he interacts directly with the buyer who place his order based on the survey/opinion of user. The persons working in finishing section and quality assurance section are the key persons involved in manufacturing and maintaining the quality. So, the judges are the experts from these sections of the textile industry. Subjective evaluation of surface texture (uniformity and orientation) was performed by 25 judges and a subjective texture rating (STR) was calculated. Mean value of rating given by all the judges has been taken for further analysis. Ranks were given on the scale of 0 to 5, 0 being the smoothest and 5 being the most rough. Kendall's coefficient of concordance $(\mathrm{W})$ is a measure of the agreement among several (k) quantitative or semiquantitative variables that are assessing a set of $n$ objects of interest. To verify the degree of agreement among judges, the coefficient of concordance has been calculated using the following formula.

$$
\mathrm{W}=\frac{12 \sum\left\{\mathrm{SR}^{2}-\mathrm{n}\left(\frac{\mathrm{SR}}{\mathrm{n}}\right)^{2}\right\}}{\mathrm{k}^{2}\left(\mathrm{n}^{3}-\mathrm{n}\right)}
$$

Where, SR: Rank Sum, k: No. of Judges, n: No. of samples

Energy, entropy and inertia were determined by using spatial grey level co-occurrence measurement method as given in equations (1), (2) and (3) respectively. Fractal dimension was calculated by using fast fourier transform (FFT). The textural parameters (energy, entropy and inertia), and fractal dimension were evaluated by using image analysis techniques according to the algorithms given. Energy is multiplied by a factor $10^{5}$ and Entropy is divided by a factor 10 to represent the data graphically.

\section{Results and Discussion}

\section{Fractal dimension and texture descriptor}

At the outset, a correlation study was carried out to examine the role of fractal dimension in describing the surface properties of apparel grade fabric. Coefficient of concordance among the judges for subjective surface roughness was found to be 0.79 which can be considered as a good agreement. The results were analysed by using Statistica Software. Image processing based texture descriptors are plotted with fractal dimension and the results are shown in Figures 5a-5d.

From the figures it can be seen that there is a negative correlation between fractal dimension \& energy while good positive correlations are observed with rest of the parameters. Higher homogeneous surface gives lower fractal dimension values and higher energy value which explains the negative correlation between fractal dimension and energy. Highly disordered surface gives high entropy value. The correlation coefficient between fractal dimension and the other texture descriptors are in the range of 0.95 to 0.99 and all the points are well within $95 \%$ confidence bounds. The results show a similar trend found by the Behera and Singh [1].

\section{Effect of weft variation on the fabric texture}

In this section, the results related to the texture change due to weft change are discussed. Since the constructional parameters of fabric, like weave, warp density, weft density etc, were kept constant, the change in the amount of weft yarn exposed per unit area on the fabric surface is also constant for all the fabrics. Figure 6 shows the rose plot of the fractal dimension of various samples. It is clearly visible from Figure 


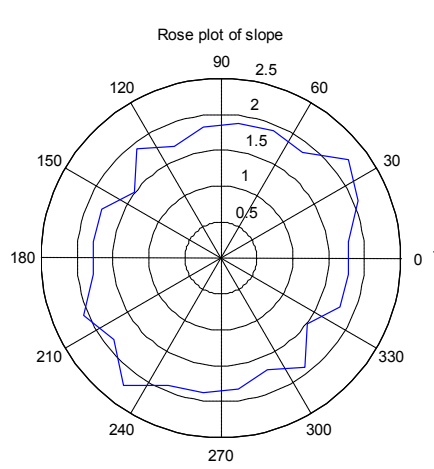

(a)

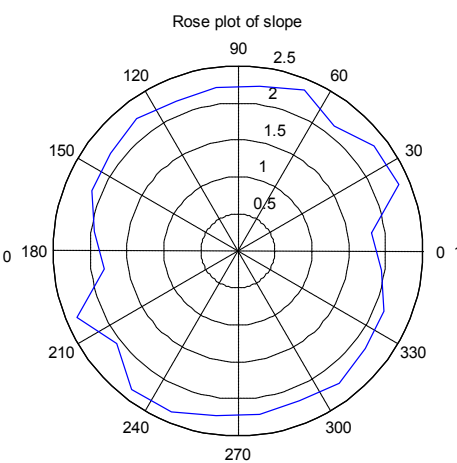

(b)

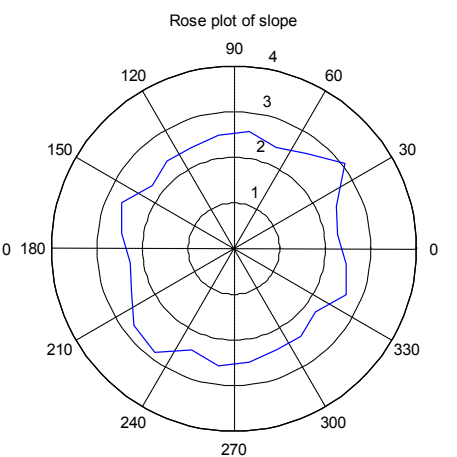

(c)

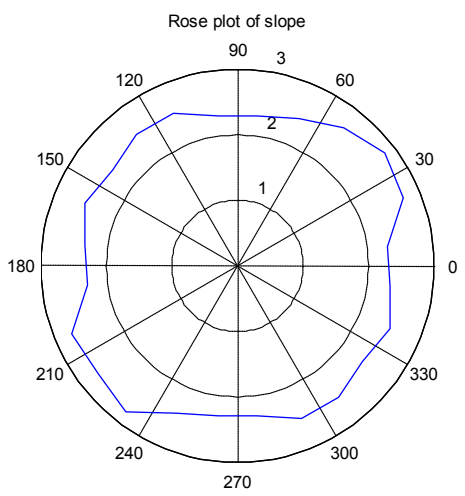

(d)

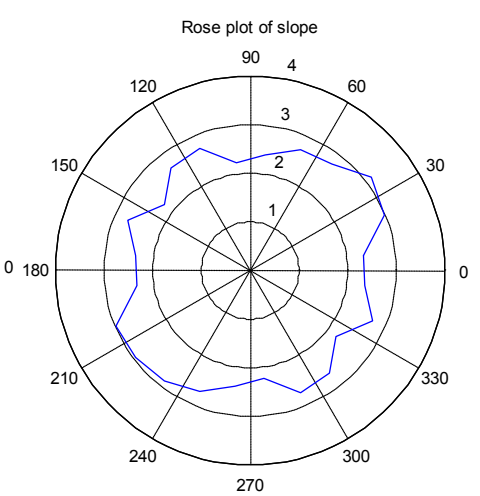

(e)

Figure 6: Rose plot of Fractal Dimension for (a) Texturised polyester filament weft (b) Combed cotton weft (c) P/V weft (d) Cotton lycra weft (e) Cotton slub weft.

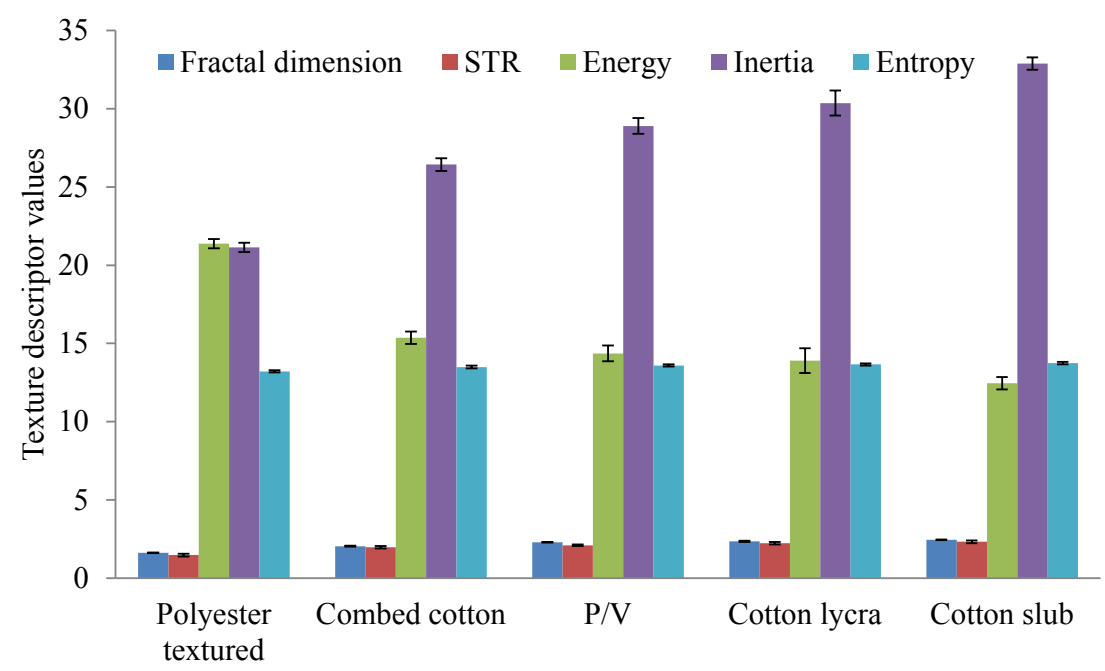

Figure 7: Texture descriptors of the surface of fabrics made from different weft.

6a that minimum fractal dimension, shown by the surface of the fabric woven with textured polyester filament yarn, is minimum among all the samples.

The next higher fractal dimension is shown by the surface of the fabric having combed cotton weft. This increase in fractal dimension is about $26 \%$ from the fabric having polyester textured filament weft. The next higher fractal dimension is shown by the surface of the fabric having $\mathrm{P} / \mathrm{V}$ weft. This increase in fractal dimension is about $30 \%$ from the fabric having polyester textured filament weft. This increase in the fractal dimension may be attributed to the discontinuous yarn surface made of staple fibre yarn. Lower fractal dimension exhibited by the surface of the fabric having combed cotton weft as compared to the one having $\mathrm{P} / \mathrm{V}$ weft may be attributed by the smoother yarn surface achieved by the finer tip of the natural cotton fibre. 
The next higher fractal dimension is shown by the surface of the fabric having cotton lycra weft. This increase in fractal dimension is about $45 \%$ from the fabric having polyester textured filament weft. The surface of the fabric having cotton slub weft exhibits highest fractal dimension. This increase in fractal dimension is about $57 \%$ from the fabric having polyester textured filament weft $[14,15]$.

Texture descriptors for various fabrics shown in the Figure 7 clearly explain the changes taking place in the fabric surface upon the change of weft yarns. The fabric having polyester textured filament yarn as weft exhibits the homogeneous texture with lower structural disorder and low local variations. These properties continue to deteriorate with the use of combed cotton weft, $\mathrm{P} / \mathrm{V}$ weft, cotton lycra weft and cotton slub weft sequentially.

The slub yarn were tested for total slub length\%, total slub distance $\%$ and total cv\% and were found $36.9,63.1$ and 46.3 respectively. As compared to the normal cotton yarn, the slub yarn is having these variations. As already mentioned, the other parameters of the fabric are constant for all the samples except the weft yarn; the additional irregularities of the weft yarn should be correlated with the change in the texture of the fabric. The percentage change in the texture descriptors are $25.37,17.17,18.95,24.44,1.85$ in fractal dimension, subjective texture rating, energy, inertia and entropy respectively. The parameters mentioned here are really not equal to any of the parameters of the slub yarn.

\section{Conclusions}

Five woven fabric samples have been prepared by changing different yarn in weft and tested for the textural properties. It is found that the fabric with textured polyester filament yarn as weft exhibits the uniform textural properties and fabric having slub yarn as weft exhibits the rough textural properties among the sample tested. The fractal dimension of the surface of the fabric with polyester textured filament weft is lowest and its rose plot is uniform in all the directions. The fractal dimension of the fabric surface keeps on increasing with change in weft from combed cotton to cotton slub weft. The rose plot of all the fabric except cotton slub weft fabric is almost uniform in all the direction which expresses its uniformity in all the direction. The disturbance in the weft yarn smoothness is the main reason behind the variation in the textural features. In this research work, a preliminary study was also done to derive the textural parameters from the geometrical parameters of the slub yarn. But the textural parameters do not seem equal to any of the geometrical parameters of the slub yarn. For this, probably a more detailed study is needed with different quality of slub yarn. The research work is in progress to give a mathematical relation between the fabric texture and slub yarn geometrical parameters. The results also suggest that all the texture results from image analysis based objective methods are very well correlated with the subjective texture results.

\section{References}

1. Lewis WJ (1977) Wool Research Organization of New Zealand. Christchurch New Zealand.

2. Ross DA (1986) Instrumental Objectivity. Textile Horizons 2: 29-30.

3. Wen CY (2001) Defect segmentation of texture images with wavelet transform and a co-occurrence matrix. Textile Research Journal. 71: 743-749.

4. Behera, BK, Singh JP (2014) Objective evaluation of aesthetic characteristics of terry pile structures using image analysis technique. Fibers and Polymers 15: 2633-2643.

5. Durrant PJ, McLaughlin JR (1984) A method for the objective measurement of carpet texture. Wool Research Organization of New Zealand, Communication no C93, Christchurch, New Zealand.

6. Haralick RM, Shanmugam K, Dinstein I (1973) Textural features for image classification. IEEE Transactions on Systems, Man and Cybernetics, SMC 3: 610-620.

7. Behera BK, Mishra R (2006). Objective measurement of fabric appearance using digital image processing. The Journal of The Textile Institute, 97: 147153.

8. Bergmann M, Herbst I, Wieding VR, Wolter FE (1999) Haptical Rendering of Rough Surfaces using Their Fractal Dimension. In Proc of the First PHANTOM Users Research Symposium, German Cancer Research Centre, Heidelberg, Germany 9-12.

9. Mandelbrot B (1983) The Fractal Geometry of Nature. Freemann, New York

10. Voss R (1988) Fractal in Nature: From Characterization to Simulation. The Science of Fractal Images, Springer-Verlag, New York 1: 21-70.

11. Zwiggelaar R, Bull CR (1995) Optical Determination of Fractal Dimensions using Fourier Transforms. Optical Engineering 34: 1325-1332.

12. Hosseini SA, Torimuki K (1995) Fourier transforms analysis of plain weave fabric appearance. Textile Research Journal 65: 676-683

13. Bailey DG, Hodgson RM (1985) Range Filters: Local intensity Sub-range Filters and their Properties. Images Vis. Computer. 3: 99-110.

14. El-khalek R, El-Bealy R, El-Deeb A (2014) A computer based system for evaluating slub yarn charecteristics. Journal of Textiles.

15. Gonzalez RC, Wood RE (1993) Digital Image Processing. Addison-Wesley, New York. 